\title{
Comparative Study of Design Berthing Energy on Fender as per Indian Standard IS4651 Part-3:1974 and British Standard BS6349 Part-4:1994
}

\author{
Dhara Shah ${ }^{1 *}$, Viral Shah ${ }^{2}$, Mehul Patel ${ }^{3}$ \\ ${ }^{I}$ Sr. Assistant professor, Faculty of Technology, CEPT University, Ahmedabad, India; dharashah@cept.ac.in \\ 2 Structural Engineer, Global Marine Engineering Consultancy, Ahmedabad, India; \\ viral.shah.mtech13@cept.ac.in \\ ${ }_{3}^{3}$ Director, Global Marine Engineering Consultancy, Ahmedabad, India; mehul.patel@pmcprojects.com
}

\section{ARTICLE INFO}

\section{Article History:}

Received: 1 Aug. 2016

Accepted: 6 Dec. 2016

\section{Keywords:}

Bulk carriers

Berthing Energy

Fender systems

berthing velocity

dead weight tonnage

\begin{abstract}
Berthing force is a critical dynamic lateral force in the design of berthing structures, having equal relevance when compared to seismic forces. Besides, the construction cost of berthing structures is very high which can be optimized by calculating precise design berthing energy on fender and selecting optimum fender system. In the present study, design berthing energy of bulk carriers having size range from 5000 DWT to 250000 DWT is compared as per Indian Standard (IS) and British Standard (BS) in terms of various berthing conditions, approach velocity, different berthing coefficients and factor of safety. It is observed that British Standard gives more precise values for design berthing velocities. However, Indian standard provides constant value of berthing velocity for vessel sizes more than 250000 DWT, which is not the case with British standard. It is also perceived that for majority of berthing conditions and vessel sizes, Indian Standard gives higher design berthing energy as compared to British Standard.
\end{abstract}

\section{Introduction}

Port transportation is one of the most important logistical systems, supporting universal movement of passengers and cargos cost effectively, thereby acting as a backbone for economic growth of country. Besides, it is the cheapest mode of transport and largest freight carrier as compared to air. The most common type of merchant ships used for freight transport are bulk carriers, container vessels, oil tankers, gas carriers, RORO ships, general cargo carriers, military ships and coastal trading vessels. Looking to the diversity of merchant ships visiting a particular port in view of their size, dead weight tonnage and type of cargo they carry, an adequate berthing facility is must to minimize the large impact spectrum of these vessels in terms of lateral force. Berthing force is one of the major forces accounted for the design of port structures. Various literature and design standards reveal that it might be a prevailing force in combination with other forces compared to seismic force. Berthing a vessel demands its kinetic energy to be absorbed / dissipated to avoid structural or vessel damage, which is done through buffers mounted on berthing structures, known as fenders. Fender systems work on the principle of high energy absorption and low reaction force. Higher the energy absorption of the fender system, lower is the lateral force on berthing structure. Selection of a wrong fender system does impact the life, safety and efficiency of the berthing structure.

\section{Governing Equations}

Impact of a docking vessel when it tries to make contact with fender units mounted on berthing structures, result in berthing force. Impact of vessel generates berthing energy which is absorbed by the fender units usually through elastic compression of their rubber elements. As the fender units are compressed, a reaction is produced which is to be resisted by the berthing structures. This reaction is the design berthing force for the structure and is a function of the size and type of fender units selected [1]. The magnitude of the berthing force depends on the kinetic energy that can be absorbed by the fender system [2]. The reaction force for which the berthing structure is to be designed can be obtained from energy-deflection-reaction diagrams of the fender given by the manufacturer.

\subsection{Berthing conditions}

Meteorological conditions during berthing of a vessel and its approach to berth can have a greater impact on 
the design berthing energy calculations than any other input. Berthing approach of a vessel can be characterized as side berthing, dolphin berthing, end berthing, at lock entrances and ship to ship berthing. Side berthing is the most typical case for ports. Site conditions considered under berthing conditions are berthing velocity of vessel, alignment of the berth relative to currents, availability of tugs, physical layout of the harbor, wave action, wind action and tidal range at time of berthing.

\subsection{Vessel characteristics}

Appropriate vessel information is must to estimate the berthing energy of a vessel. Critical inputs pertaining to vessel in order to calculate berthing energy are vessel size, shape and mass. In the present study, design berthing energy of bulk carriers with sizes varying from 5000 DWT to 250000 DWT has been calculated. The statistical information for the vessels considered is given in Table 1 below. DWT is the dead weight tonnage i.e. the weight in tons of cargo, stores, fuel, passengers and crew carried by the vessel when loaded to her maximum summer load line. Displacement tonnage - DT is the actual weight of the vessel or the weight of $t$ water she displaces when afloat and may be either 'loaded' or 'light'. Displacement, loaded is the weight, in long tons, of the ship and its contents when fully loaded with cargo, to the Plimsoll mark or load line. Displacement, light, is the weight, in long tons, of the ship without cargo, fuel and stores.

Table 1. Ship Characteristic [3]

\begin{tabular}{|c|c|c|c|c|c|c|c|}
\hline $\begin{array}{l}\text { Vessel } \\
\text { Type }\end{array}$ & $\begin{array}{c}\text { DWT } \\
\text { (T) }\end{array}$ & $\begin{array}{l}\text { DT } \\
(\mathbf{T})\end{array}$ & $\begin{array}{c}\text { Overall } \\
\text { Length } \\
(\mathrm{m})\end{array}$ & $\begin{array}{l}\text { PP } \\
(\mathbf{m})\end{array}$ & $\begin{array}{c}\text { Breadt } \\
\text { h } \\
(\mathrm{m})\end{array}$ & $\begin{array}{c}\text { Depth } \\
\text { (m) }\end{array}$ & $\begin{array}{c}\text { Max. } \\
\text { Draft } \\
(\mathrm{m})\end{array}$ \\
\hline \multirow[t]{12}{*}{$\begin{array}{c}\text { Bulk } \\
\text { Carrier }\end{array}$} & 5000 & 6740 & 106 & 98 & 15 & 8.4 & 6.1 \\
\hline & 7000 & 9270 & 116 & 108 & 16.6 & 9.3 & 6.7 \\
\hline & 10000 & 13000 & 129 & 120 & 18.5 & 10.4 & 7.5 \\
\hline & 15000 & 19100 & 145 & 135 & 21 & 11.7 & 8.4 \\
\hline & 20000 & 25000 & 157 & 148 & 23 & 12.8 & 9.2 \\
\hline & 30000 & 36700 & 176 & 167 & 26.1 & 14.4 & 10.3 \\
\hline & 50000 & 59600 & 204 & 194 & 32.3 & 16.8 & 12 \\
\hline & 70000 & 81900 & 224 & 215 & 32.3 & 18.6 & 13.3 \\
\hline & 100000 & 115000 & 248 & 239 & 37.9 & 20.7 & 14.8 \\
\hline & 150000 & 168000 & 279 & 270 & 43 & 23.3 & 16.7 \\
\hline & 200000 & 221000 & 303 & 294 & 47 & 25.4 & 18.2 \\
\hline & 250000 & 273000 & 322 & 314 & 50.4 & 27.2 & 19.4 \\
\hline
\end{tabular}

\subsection{Fendering principle}

Necessity to use economical fendering system arises so as to minimize the life - construction and operation costs, accommodate majority of ship types and sizes, requirement of deeper water mooring and berthing and safety of staff, ships and waterfront structures. Fendering is basically the interface between a vessel and the berth facility, which absorbs a certain portion of the kinetic energy of a vessel without damaging the vessel and the berthing structure. Mostly rubber fenders absorb majority of the energy by deflecting elastically. However, deflection of the berth structure and vessel's hull do contribute in absorbing kinetic energy. The energy absorbed by the fender system through compression is partially reverted to the vessel and partially dissolute in the form of heat within the material. The reaction force generated in fender system when multiplied by the deflection and a certain efficiency factor equals the kinetic energy, which is given as:

$E_{f}=F R_{m} d_{m}$

where,

$E_{f}=$ Vessel's kinetic energy to be absorbed by the fender system $(\mathrm{kJm})$

$\mathrm{F}=$ Factor representing the energy absorbing efficiency of the fender system (between 0 and 1)

$R_{m}=$ Maximum fender reaction force $(\mathrm{kN})$

$d_{m}=$ Maximum fender deflection (m)

Factor $\mathrm{F}$ entirely depends on the fender characteristics i.e. the relation between deflection and reaction force as shown in Figure1. The shaded area in the figure represents the energy absorption. Factor $\mathrm{F}$ is equal to the shaded area divided by the rectangular area $\mathrm{O}-\mathrm{R}_{\mathrm{m}}$ A- $\mathrm{d}_{\mathrm{m}}$. Each fender must have the proficiency to absorb the full impact energy as the vessel in majority of the cases contact only one fender at first impact.
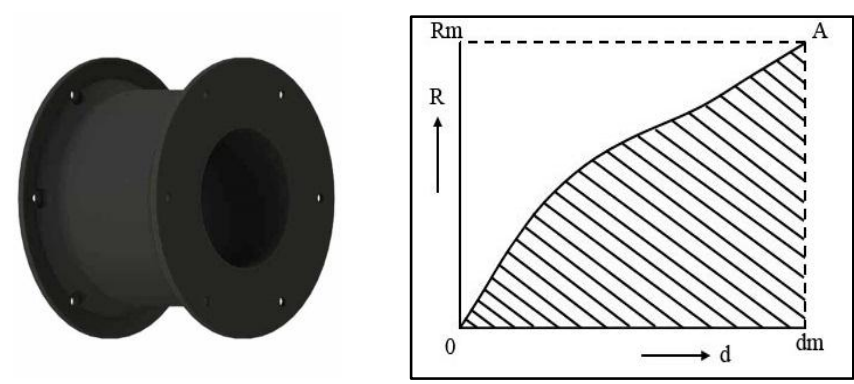

Figure 1. Schematic of cell fender and energy absorption Curve [3]

Hence it becomes vital to select an optimum fender system, designed and manufactured as per the functional and operational requirements of the specific port and terminal in order to optimize significant investment made, reduce interruption and maintenance needs as well as maximizing fender's desired service life. Selecting an appropriate fender system does have a major impact on the overall project cost. 


\section{Berthing energy calculation}

Ship's berthing energy is proportional to the virtual mass of the ship and the square of approach velocity. It gets reduced by eccentric berthing, wherein the ship rotates and hits the berth at a distance from its center of gravity. The berthing energy due to the impact of vessel on berthing structure is based on the basic equation of kinetic energy given as

$E=0.5 m v^{2}$

where,

$\mathrm{E}=$ kinetic energy in $\mathrm{kNm}$

$m=$ mass of the vessel in Tonne

$v=$ approach velocity of the vessel normal to berth, in

$\mathrm{m} / \mathrm{s}$

The kinetic energy of the vessel calculated as above does not have to be absorbed totally by the fender system. Generally, the required fender system energy is expressed as a factor C, times the vessel's kinetic energy given as

$E=C * 0.5 m v^{2}$

where, $C$ is the berthing coefficient made up of different factors and vary as per the standards of a particular country.

\subsection{Berthing energy as per Indian Standard}

As per Indian standard IS4651 part-3 [2], the normal berthing energy is given as:

$E_{N}=\frac{W_{D} v^{2}}{2 g} C_{m} C_{e} C_{s}$

where,

$W_{D}=$ Displacement tonnage (DT) of the vessel in tonnes

$v=$ Approach velocity of the vessel in $\mathrm{m} / \mathrm{s}$, normal to berth

$g=$ Acceleration due to gravity in $\mathrm{m} / \mathrm{s}^{2}$

$C_{m}=$ Mass coefficient

$C_{e}=$ Eccentricity coefficient

$C_{S}=$ Softness coefficient

\subsubsection{Approach velocity of vessel}

Approach velocity is defined as vessel's speed at first berthing contact and measured normal to the berth line. Indian standard has provided the normal components of approach velocities for different meteorological conditions as well as dead weight tonnage (DWT) of the berthing vessels. Indian standard has specified five metocean berthing conditions, varying from easy berthing to difficult berthing in a tabular format as shown in Table 2. In the table, sheltered -favorable condition can be presumed as easy berthing while strong wind and swell - difficult condition can be idealized as critical condition for berthing. Severity of berthing condition decreases as we move from first row to last row. But the standard is vague regarding berthing velocity for intermediate sizes of vessels.

Table 2. Berthing velocity of vessels as per Indian standard Berthing velocity normal to berth in $(\mathrm{m} / \mathrm{s})$

\begin{tabular}{|c|c|c|c|c|c|c|}
\hline \multirow[b]{2}{*}{$\begin{array}{l}\text { Sr. } \\
\text { no }\end{array}$} & \multirow[b]{2}{*}{$\begin{array}{c}\text { Site } \\
\text { condition }\end{array}$} & \multirow[b]{2}{*}{$\begin{array}{l}\text { Berthing } \\
\text { condition }\end{array}$} & \\
\hline & & & $\begin{array}{c}\text { up to } \\
5000 \\
\text { DT }\end{array}$ & $\begin{array}{c}\text { up to } \\
10000 \\
\text { DT }\end{array}$ & $\begin{array}{c}\text { up to } \\
100000 \\
\text { DT }\end{array}$ & $\begin{array}{c}\text { more } \\
\text { than } \\
100000 \\
\text { DT }\end{array}$ \\
\hline 1 & $\begin{array}{l}\text { Strong wind } \\
\text { and swells }\end{array}$ & Difficult & 0.75 & 0.55 & 0.40 & 0.20 \\
\hline 2 & $\begin{array}{l}\text { Strong wind } \\
\text { and swells }\end{array}$ & Favorable & 0.60 & 0.45 & 0.30 & 0.20 \\
\hline 3 & $\begin{array}{c}\text { Moderate } \\
\text { wind and } \\
\text { swells }\end{array}$ & Moderate & 0.45 & 0.35 & 0.20 & 0.15 \\
\hline 4 & Sheltered & Difficult & 0.25 & 0.20 & 0.15 & 0.10 \\
\hline 5 & Sheltered & Favorable & 0.20 & 0.25 & 0.10 & 0.10 \\
\hline
\end{tabular}

\subsubsection{Mass coefficient $-C_{m}$}

Mass coefficient $-C_{m}$, is hydrodynamic or added mass factor, which considers the mass of water surrounding and moving with the vessel when it hits fenders. This mass of water is known as additional weight which adds to the energy possessed by the vessel. When the fenders stop the vessel, the thrust of the entrained water continues to push against the vessel and hence increases its overall mass. Added mass factor also depend on water depth, underkeel clearance, underwater shape of the vessel. As per Indian standard, $C_{m}$ depends on the size as well as displacement tonnage of the vessel. The mass coefficient is calculated as:

$C_{m}=1+\frac{2 D}{B}$ vessels with DT $<20000$

$C_{m}=1+\frac{\frac{\pi}{4} D^{2} \mathrm{Lw}}{W_{D}}$ vessels with DT $\geq 20000$

where,

$D=$ Fully loaded draught of the vessel in $\mathrm{m}$

$B=$ Beam of the vessel in $\mathrm{m}$

$L=$ Length of the vessel in $\mathrm{m}$

$\mathrm{w}=$ unit weight of water $=1.03$ tonne $/ \mathrm{m}^{3}$ for sea

$W_{D}=$ Displacement tonnage of the vessel in tonne

\subsubsection{Eccentricity coefficient $-C_{e}$}

Eccentricity coefficient - $C_{e}$, depends on the location of the point of impact of the vessel with respect to its center of gravity. Generally, berthing of a vessel is at an angle $-\theta$, with either bow or stern touching the berth. The vessel rotates around the point of impact with the fenders and hence dissipates energy, which is accounted by eccentricity coefficient $-C_{e}$. To calculate accurately the eccentricity coefficient, the exact point of impact, berthing angle and velocity vector angle are important. The eccentricity coefficient is calculated as:

$C_{e}=\frac{1+(l / r)^{2} \sin ^{2} \theta}{1+(l / r)^{2}}$

where, 
$l=$ Distance from the center of gravity of the vessel to the point of contact projected along the water line of the berth in $\mathrm{m}$ as shown in Figure 2.

$r=$ Radius of gyration of rotational radius on the plane of the vessel from its center of gravity in $m$ $\theta=$ Approach angle of the vessel

Indian standard provides eccentricity coefficient values for different $l / \mathrm{r}$ ratio as shown in Table 3 .

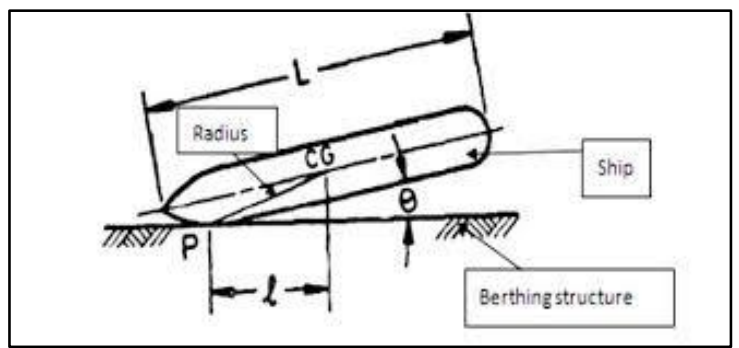

Figure 2. Geometry of vessel approach to berth as per Indian standard

Table 3. Eccentricity coefficient values as per Indian Standard Angle $\theta$

\begin{tabular}{cccc}
\hline $\boldsymbol{l} / \boldsymbol{r}$ & $\mathbf{0}^{\mathbf{0}}$ & $\mathbf{1 0}^{\mathbf{0}}$ & $\mathbf{2 0}^{\mathbf{0}}$ \\
\hline 1 & 0.5 & 0.51 & 0.56 \\
\hline 1.25 & 0.39 & 0.41 & 0.46 \\
\hline
\end{tabular}

\subsubsection{Softness coefficient $-\mathrm{C}_{\mathrm{s}}$}

The softness factor $-C_{s}$, specifies the relation between the rigidity of the vessel and the fender. This is the portion of berthing energy absorbed by the vessel's hull and the fender. It is normally assumed as 0.95 for soft fenders and 0.9 for hard fenders.

\subsubsection{Factor of safety $-F_{s}$}

Anomalous impacts arise when the normal berthing energy on the fender exceeds due to human error, malfunctions, exceptional weather conditions or a combination of all. This is accounted by factor of safety $-F_{s}$. The factor of safety considers any potential risk related with berthing and navigational conditions, the consequence of fender failure to the operation of a particular berth, hazardous and valuable cargoes including people, frequency of berth usage, load sensitivity of the structure, range of vessel sizes and types using the berth and any other factor that may affect the ability to safely berth the vessels. Indian Standard recommends a factor of safety as 1.4 to be multiplied to normal berthing energy to get design berthing energy. Hence design berthing energy - $E_{D}$ as per Indian Standard is given as

$$
E_{D}=1.4 E_{N}
$$

\subsection{Berthing energy as per British Standard}

As per British Standard BS6349 part-4 [4], the normal berthing energy is given as:

$E_{N}=0.5 M_{D}\left(V_{B}\right)^{2} C_{M} C_{E} C_{S} C_{C}$ where,

$M_{D}=$ Displacement tonnage (DT) of the vessel in tonnes

$V_{B}=$ Approach velocity of the vessel in $\mathrm{m} / \mathrm{s}$, normal to berth

$C_{M}=$ Hydrodynamic mass coefficient

$C_{E}=$ Eccentricity coefficient

$C_{S}=$ Softness coefficient

$C_{C}=$ Berth configuration coefficient

\subsubsection{Approach velocity of vessel}

British standard has specified five berthing velocities as per the navigation conditions and size of the vessel as shown in Figure 3. The navigation conditions are:

a) Good berthing, sheltered

b) Difficult berthing, sheltered

c) Easy berthing exposed

d) Good berthing, exposed

e) Navigation conditions difficult, exposed

British standard has specified berthing velocity of vessel with respect to site conditions in graphical form. Each curve represents different navigation condition. Hence interpolated values can be obtained for intermediate size of vessels having different navigation conditions. British standard gives precise values of berthing velocity as compared to Indian standard.

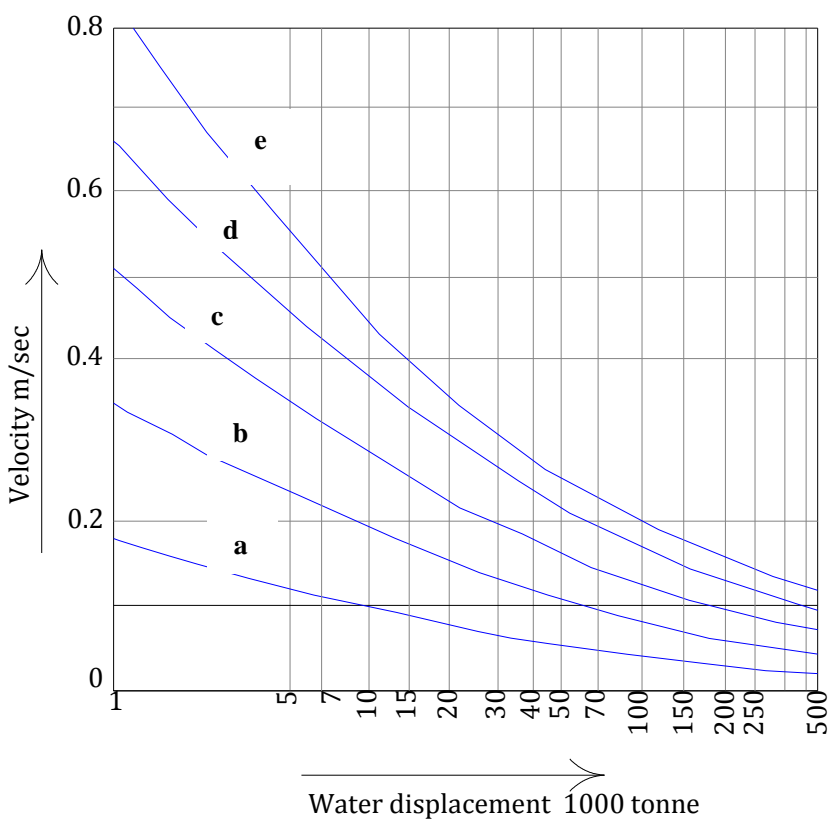

Figure 3. Design berthing velocity as per British Standard

\subsubsection{Hydrodynamic mass coefficient - $C_{M}$}

As per British standard, $C_{M}$ for any size of vessel is calculated as

$C_{M}=1+\frac{2 D}{B}$

where,

$D=$ Fully loaded draught of the vessel in $\mathrm{m}$

$B=$ Beam of the vessel in $\mathrm{m}$ 
$C_{M}$ value generally ranges from 1.3 to 1.8 as per the above formula.

\subsubsection{Eccentricity coefficient - $C_{E}$}

As per British standard, the eccentricity coefficient$\mathrm{C}_{\mathrm{E}}$, is calculated as

$C_{E}=\frac{K^{2}+R^{2} \operatorname{Cos}^{2} \gamma}{K^{2}+R^{2}}$

where,

$K=$ Radius of gyration of the vessel and is calculated as

$\mathrm{K}=\left(0.19 C_{b}+0.11\right) L$

where,

$L=$ Length of the hull between perpendiculars

$C_{b}=$ Block coefficient, a function of hull shape and is given as

$C_{b}=\frac{M_{D}}{\mathrm{~L} B D \mathrm{w}}$

where,

$M_{D}=$ Displacement tonnage (DT) of the vessel in tonnes

$L=$ Length of the hull between perpendiculars

$B=$ Beam of the vessel in $\mathrm{m}$

$D=$ Fully loaded draught of the vessel in $\mathrm{m}$

$\mathrm{w}=$ unit weight of water $=1.03$ tonnes $/ \mathrm{m}^{3}$ for sea

$D=$ Distance of point of contact of vessel from the center of mass in $\mathrm{m}$

$\gamma=$ Angle between the line joining point of contact to the center of mass and the velocity vector as shown in Figure 4.

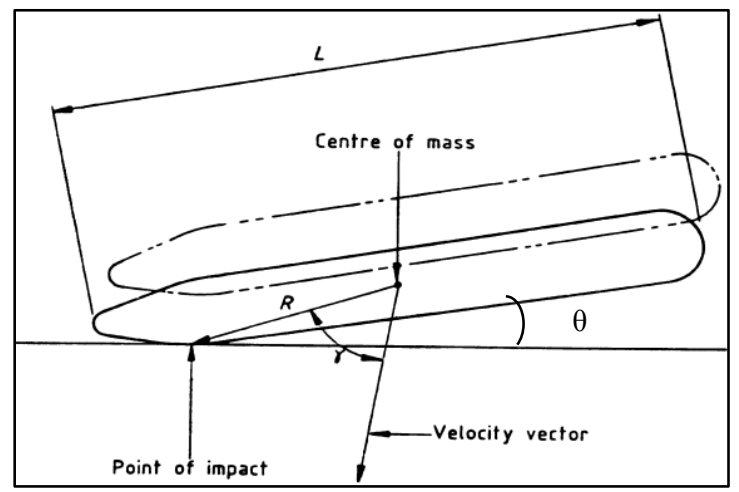

Figure 4. Geometry of vessel approach to berth as per British standard

British standard lists typical ranges of value for the block coefficient for various vessel types as shown in Table 4.

Table 4. Block coefficient values as per British Standard

\begin{tabular}{ll}
\hline Vessel Type & Range of $\boldsymbol{C}_{\boldsymbol{b}}$ \\
\hline Tanker / Bulk & 0.72 to 0.85 \\
\hline Container & 0.65 to 0.70 \\
\hline Ro-Ro & 0.65 to 0.70 \\
\hline Passenger & 0.65 to 0.70 \\
\hline Dry cargo / combi & 0.60 to 0.75 \\
\hline Ferry & 0.50 to 0.65 \\
\hline
\end{tabular}

\subsubsection{Softness coefficient $-\mathrm{C}_{S}$}

As per the British standard, the softness coefficient allows for the portion of the impact energy that is absorbed by the ship's hull. Generally the value of $\mathrm{C}_{\mathrm{S}}$ lies between 0.9 and 1.0. For ships which are fitted with continuous rubber fendering, $\mathrm{C}_{\mathrm{S}}$ may be taken to be 0.9. For all other vessels, $\mathrm{C}_{\mathrm{S}}=1.0$.

\subsubsection{Berth configuration coefficient $-\mathrm{C}_{C}$}

As per British standard, when vessel berths at small angles against solid structures, the water between hull and quay acts as a cushion and dissipates a small part of the berthing energy, which is accounted by berth configuration coefficient. It depends on several factors such as type of quay construction and its distance from the side of the vessel, berthing angle, shape of vessel's hull and its under keel clearance. For open piled jetty structure, $\mathrm{C}_{\mathrm{C}}$ is taken as 1.0 whereas for a solid quay wall, $\mathrm{C}_{\mathrm{C}}$ is taken in between 0.8 and 1.0.

\subsubsection{Factor of safety $-F_{s}$}

Anomalous impacts arise when the normal berthing energy on the fender exceeds due to human error, malfunctions, exceptional weather conditions or a combination of all. This is accounted by factor of safety $-\mathrm{F}_{\mathrm{s}}$. British Standard recommends a factor of safety as 2.0 to be multiplied to normal berthing energy to get design berthing energy. Hence design berthing energy $-E_{D}$ as per British Standard is given as

$E_{D}=2.0 E_{N}$

\section{Results and Discussions}

The design berthing energy of bulk carriers with stated sizes have been calculated numerically and compared using the formulae as per Indian standard and British standard. The heads for the discussions are as follows:

\subsection{Approach velocity}

Approach velocities as per Indian standard and British standard are correlated as per five metocean conditions and compared. The results are shown in Figure 5, 6, 7, 8 and 9.

As observed, for all five metocean conditions, British standard gives precise values of berthing velocity as compared to Indian standard. Hence interpolated values for intermediate size of vessels having different navigation conditions can be obtained easily. Also, Indian standard provides constant value of berthing velocity for vessel having DWT more than 250,000, which is not the case with British standard. Graphical representation gives more clarity. 


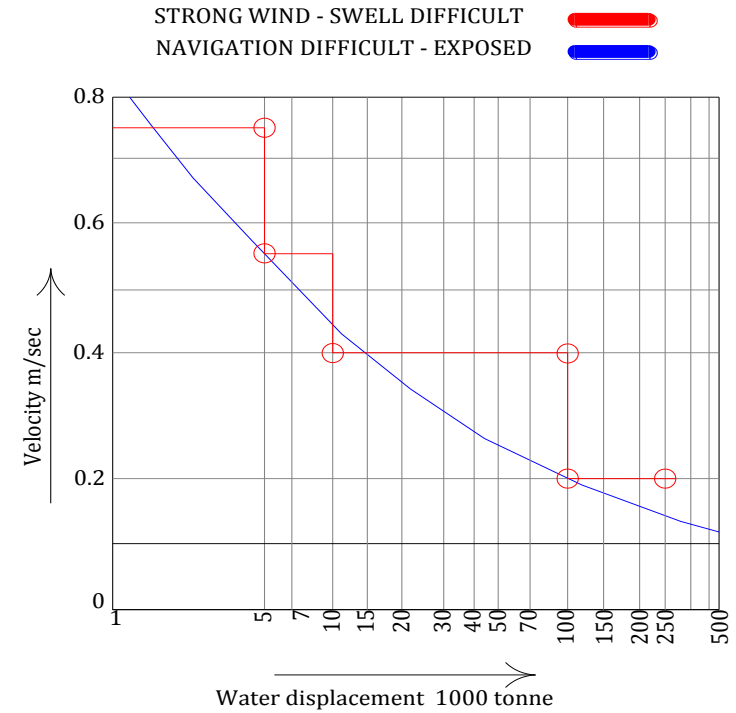

Figure 5. Berthing velocity: strong wind and swells - difficult (IS) and Navigation difficult - exposed (BS)

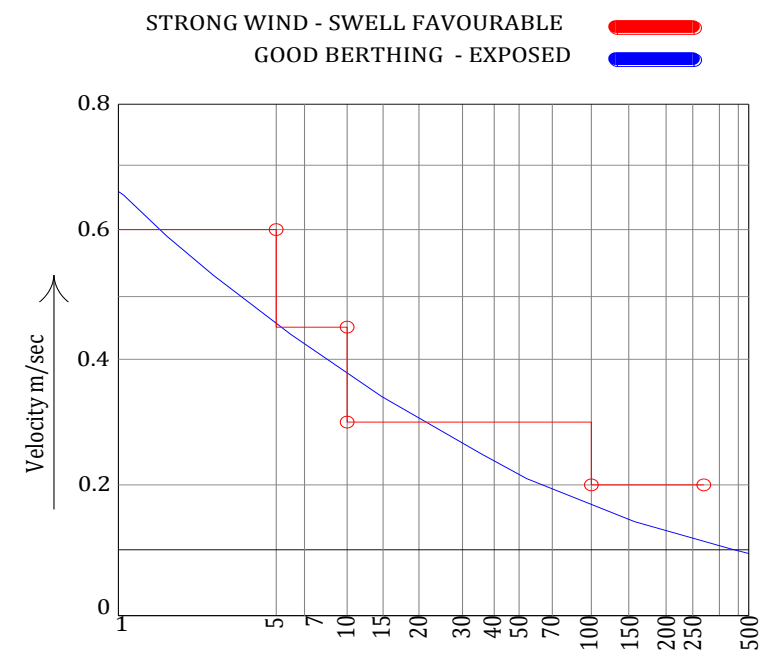

Figure 6. Berthing velocity: strong wind and swells - favorable (IS) and good berthing - exposed (BS)

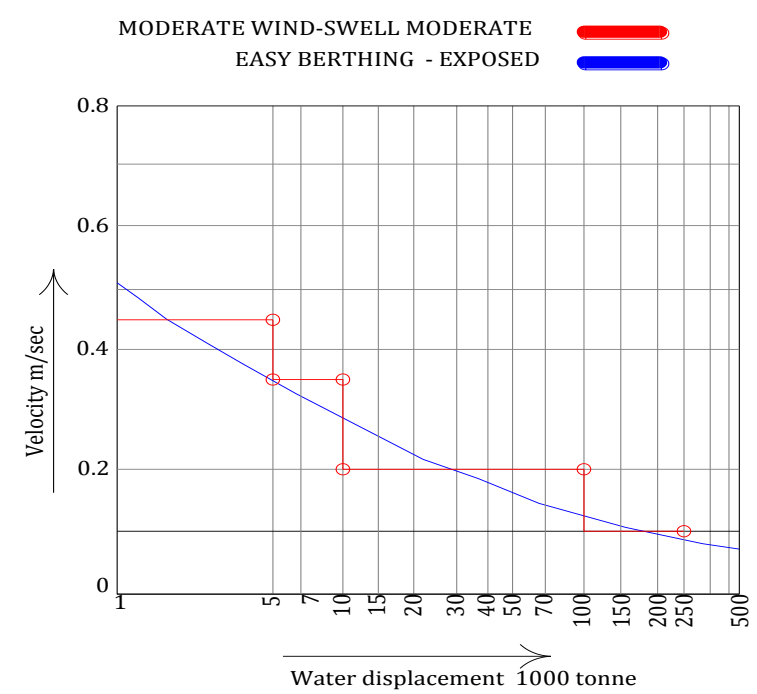

Figure 7. Berthing velocity: Moderate wind and swellsmoderate (IS) and Easy berthing - exposed (BS

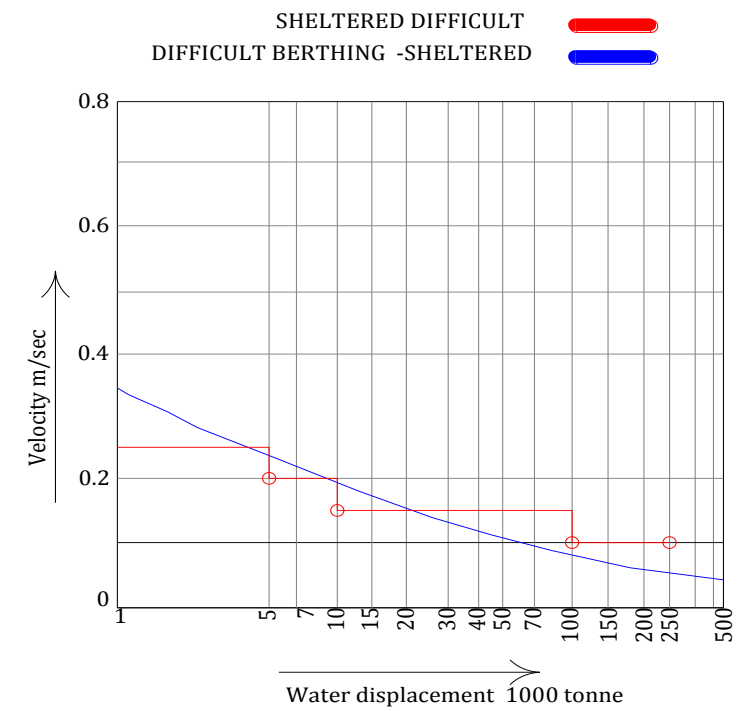

Figure 8. Berthing velocity: sheltered - difficult (IS) and Difficult berthing - sheltered (BS)

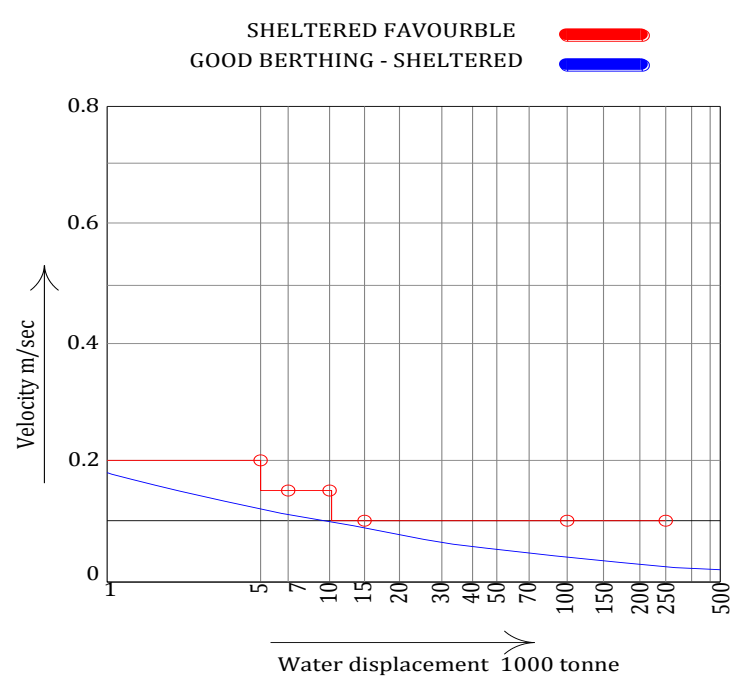

Figure 9. Berthing velocity: sheltered - favorable (IS) and good berthing - sheltered (BS)

\subsection{Mass coefficient $-C_{m}$}

As per Indian Standard, mass coefficient is dependent on the size as well as displacement tonnage of the berthing vessel. As per British standard, mass coefficient is independent of displacement tonnage of the berthing vessel. The comparison of mass coefficient for different sizes of bulk carriers as per Indian standard and British standard is shown below in Figure 10 and Table 5. Difference in the values of $\mathrm{C}_{\mathrm{m}}$ is observed when vessel size increases from 15000 DWT to 250000 DWT.

\subsection{Eccentricity coefficient $-C_{e}$}

As per Indian standard, eccentricity coefficient depends on the length of the vessel and approach angle of the vessel measured between the distance of point of contact to the center of gravity of the vessel and water line of the berth. It is irrespective of the vessel size. In British standard, eccentricity coefficient 
depends on the size of the vessel and angle measured between the distance of point of contact to the center of mass of the vessel and velocity vector. Table 6 below provides the comparison of $\mathrm{C}_{\mathrm{e}}$ values for different berthing angle as per Indian standard and British standard.

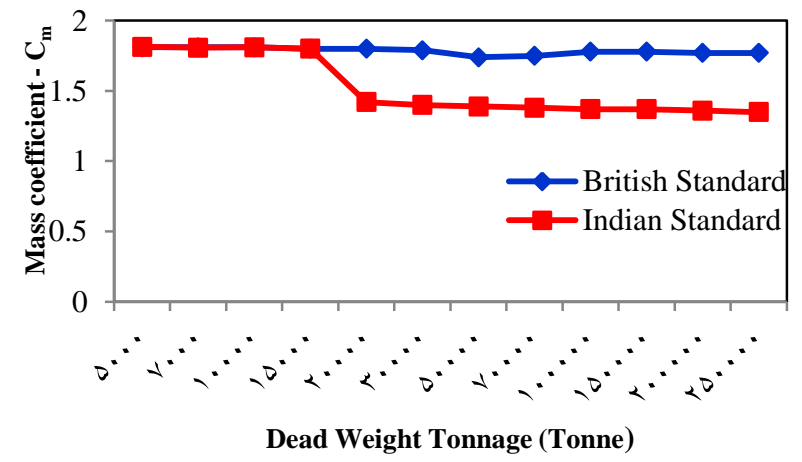

Figure 10. Comparison of mass coefficient as per Indian \& British Standard

Table 5. Comparison of mass coefficient as per Indian \& British Standard

\begin{tabular}{ccc}
\hline Dead weight Tonnage (DWT) & British Standard & $\begin{array}{c}\text { Indian } \\
\text { Standard }\end{array}$ \\
\hline 5000 & 1.81 & 1.81 \\
\hline 7000 & 1.81 & 1.81 \\
\hline 10000 & 1.81 & 1.81 \\
\hline 15000 & 1.81 & 1.81 \\
\hline 20000 & 1.79 & 1.42 \\
\hline 30000 & 1.78 & 1.40 \\
\hline 50000 & 1.74 & 1.39 \\
\hline 70000 & 1.75 & 1.38 \\
\hline 100000 & 1.78 & 1.37 \\
\hline 150000 & 1.78 & 1.37 \\
\hline 200000 & 1.77 & 1.36 \\
\hline 250000 & 1.77 & 1.35 \\
\hline
\end{tabular}

Table 6. Comparison of eccentricity coefficient as per Indian \& British Standard

\begin{tabular}{ccccccc}
\hline $\begin{array}{c}\text { Vessel size } \\
\text { DWT }\end{array}$ & \multicolumn{3}{c}{$\mathbf{C}_{\mathbf{e}}$ - Indian Standard } & \multicolumn{2}{c}{$\mathbf{C}_{\mathbf{e}}$ - British standard } \\
\cline { 2 - 7 } & $\begin{array}{c}\boldsymbol{\theta}= \\
\mathbf{0}^{\mathbf{o}}\end{array}$ & $\begin{array}{c}\boldsymbol{\theta}= \\
\mathbf{1 0}^{\mathbf{0}}\end{array}$ & $\begin{array}{c}\boldsymbol{\theta}= \\
\mathbf{2 0}^{\mathbf{0}}\end{array}$ & $\begin{array}{c}\boldsymbol{\theta}= \\
\mathbf{0}^{\mathbf{o}}\end{array}$ & $\begin{array}{c}\boldsymbol{\theta}= \\
\mathbf{1 0}^{\mathbf{0}}\end{array}$ & $\begin{array}{c}\boldsymbol{\theta}= \\
\mathbf{2 0}^{\mathbf{0}}\end{array}$ \\
\hline 5000 & 0.5 & 0.522 & 0.586 & 0.465 & 0.466 & 0.484 \\
\hline 7000 & 0.5 & 0.522 & 0.586 & 0.476 & 0.477 & 0.494 \\
\hline 10000 & 0.5 & 0.522 & 0.586 & 0.479 & 0.48 & 0.497 \\
\hline 15000 & 0.5 & 0.522 & 0.586 & 0.487 & 0.488 & 0.505 \\
\hline 20000 & 0.5 & 0.522 & 0.586 & 0.492 & 0.493 & 0.51 \\
\hline 30000 & 0.5 & 0.522 & 0.586 & 0.502 & 0.503 & 0.52 \\
\hline 50000 & 0.5 & 0.522 & 0.586 & 0.494 & 0.495 & 0.513 \\
\hline 70000 & 0.5 & 0.522 & 0.586 & 0.532 & 0.533 & 0.548 \\
\hline 100000 & 0.5 & 0.522 & 0.586 & 0.524 & 0.525 & 0.542 \\
\hline
\end{tabular}

\begin{tabular}{ccccccc}
\hline 150000 & 0.5 & 0.522 & 0.586 & 0.529 & 0.53 & 0.547 \\
\hline 200000 & 0.5 & 0.522 & 0.586 & 0.535 & 0.536 & 0.552 \\
\hline 250000 & 0.5 & 0.522 & 0.586 & 0.541 & 0.542 & 0.558
\end{tabular}

4.4. Softness coefficient - $C_{s}$

Softness coefficient is almost similar in both the standards.

\subsection{Berth configuration coefficient $-\mathrm{C}_{\mathrm{c}}$}

Such coefficient does not exist in Indian standard. Softness coefficient is almost similar in both the standards. As per British standard, for open piled jetty structure, $\mathrm{C}_{\mathrm{C}}$ is taken as 1.0 whereas for a solid quay wall, $\mathrm{C}_{\mathrm{C}}$ is taken in between 0.8 and 1.0.

\subsection{Factor of safety $-F_{s}$}

Indian Standard recommends a factor of safety as 1.4 to be multiplied to normal berthing energy to get design berthing energy while British Standard recommends a factor of safety as 2.0 to be multiplied to normal berthing energy to get design berthing energy.

\subsection{Design berthing energy for bulk carriers}

Considering all above factors, design berthing energy for bulk carriers is calculated as per Indian Standard and British Standard for five metocean conditions and compared in chart form as shown in Figure $11,12,13,14$ and 15 .

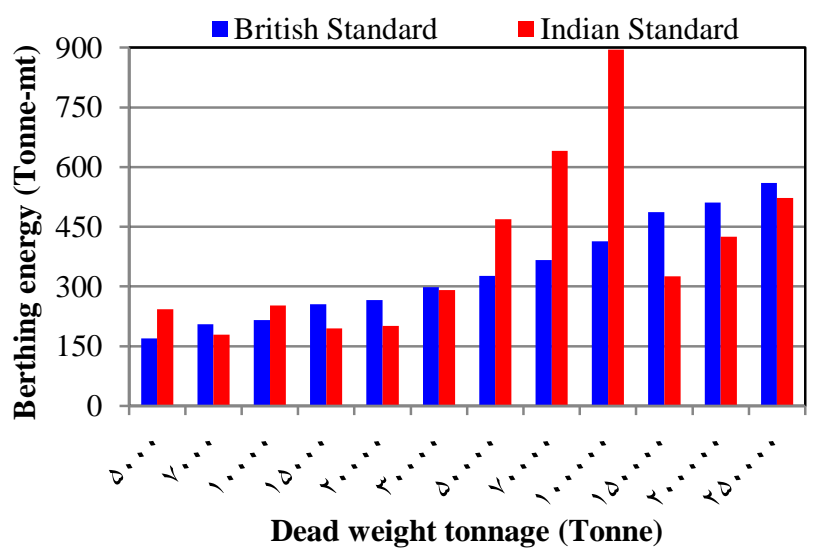

Figure 11. Berthing velocity: strong wind and swell - difficult (IS) and Navigation difficult - exposed (BS)

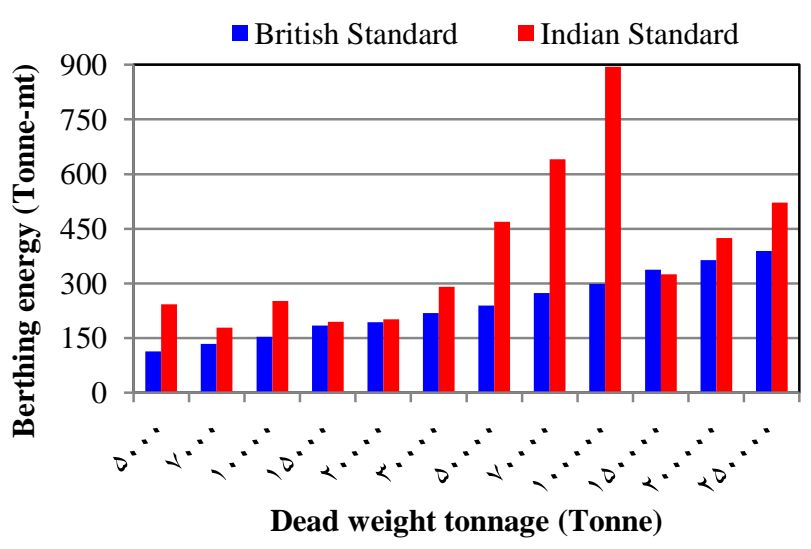


Figure 12. Berthing velocity: strong wind and swell - favorable (IS) and good berthing- exposed (BS)

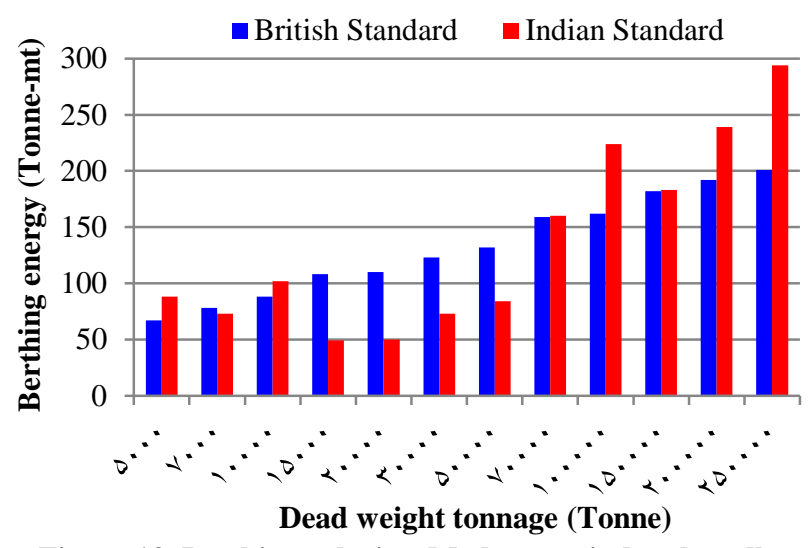

Figure 13. Berthing velocity: Moderate wind and swell moderate (IS) and Easy berthing - exposed (BS)

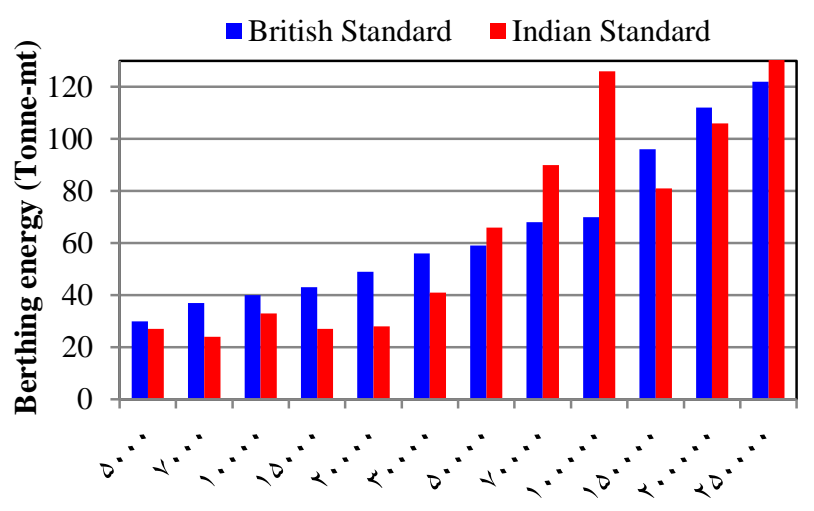

Dead weight tonnage (Tonne)

Figure 14. Berthing velocity: Sheltered - difficult (IS) and Difficult berthing - sheltered (BS)

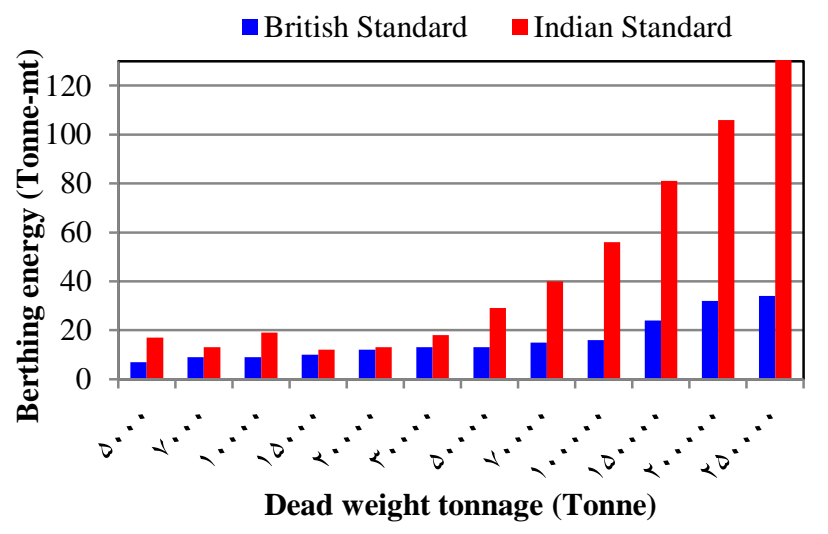

Figure 15. Berthing velocity: sheltered - favorable (IS) and good berthing - sheltered (BS)

\section{Conclusions}

- Strong wind and swell - difficult (IS) and Navigation difficult- exposed (BS)

In this berthing condition, Indian standard gives higher design berthing energy for vessels having sizes as 5000 DWT, 10000 DWT and from 50000 DWT to 100000 DWT. For rest of the vessels sizes, British standard governs. Disparity in design berthing energy between the two standards is mainly due to the variances in approach velocities, mass coefficient, eccentric coefficient and factor of safety.

- Strong wind and swell - favourable (IS) and Good berthing - exposed (BS)

In this condition, British standard gives higher value of design berthing energy for vessel size 150000 DWT. For rest of the vessel sizes, Indian standard governs.

- Moderate wind and swell - moderate (IS) and Easy berthing- exposed (BS)

In this berthing condition, Indian standard gives higher design berthing energy for vessels having sizes as 5000 DWT, 10000 DWT and from 70000 DWT to 250000 DWT. For rest of the vessels sizes, British standard governs.

- Sheltered - difficult (IS) and Difficult berthing - Sheltered (BS)

In this berthing condition, British standard gives higher design berthing energy for vessels having sizes from 5000 DWT to 30000 DWT and from 150000 DWT to 200000 DWT. For rest of the vessels sizes, Indian standard governs.

- Sheltered - favorable (IS) and Good berthing Sheltered (BS)

In this berthing condition, Indian standard gives higher design berthing energy for all vessel sizes.

\section{List of Symbols PP \\ Length of vessel between perpendicular}

\section{References}

1- TERMPOL, (2010), Enbridge northern gateway project, section 3.13 - Berth procedures and provisions, Northern gateway pipelines Inc.

2- IS4651 Part-3, (1974), Code of practice for planning and design of ports and harbours - Loading, Bureau of Indian Standards, New Delhi.

3 - PIANC, (2002), Guidelines for the Design of Fender Systems, Marcom report of WG 33, International Navigation Association, Brussels, Belgium.

4- BS6439 part-4, (1994), Maritime structures: Code of practice for design of fendering and mooring systems, British Standard. 